\title{
Relato de possibilidades de ensino com ferramentas digitais em tempos de pandemia
}

As experiências com ensino em tempos de pandemia modificam metodologias estabelecidas e consequentemente, há reflexos na construção de aprendizados entre estudantes com a utilização de ferramentas digitais. A pesquisa foi desenvolvida com uma abordagem qualitativa, através de artigos, dissertações, livros, e quantitativa, aliando os pressupostos teóricos aos dados obtidos a partir do preenchimento das planilhas de inscrição pelos participantes de um curso. Considera-se que as ferramentas à disposição dos estudantes em modalidade assíncrona se mostram viabilizadoras de construções de conhecimentos. A educação precisa funcionar como um aporte para a transformação social e promoção da autonomia, a fim de que se desconstruam de paradigmas estabelecidos historicamente. A educação deve ultrapassar os limites acadêmicos e fortalecer a democratização dos saberes.

Palavras-chave: Ferramentas digitais; Ensino remoto; Relatos; Atividades assíncronas.

\section{Reporting of teaching possibilities with digital tools in times of pandemic}

\begin{abstract}
Experiences with teaching in times of pandemic change established methodologies and, consequently, there are consequences in the construction of learning among students with the use of digital tools. The research was developed with a qualitative approach, through articles, dissertations, books, and quantitative, combining the theoretical assumptions with the data obtained from the completion of the registration spreadsheets by the participants of a course. It is considered that the tools available to students in asynchronous mode are shown to enable knowledge construction. Education needs to function as a contribution to social transformation and promotion of autonomy, in order to deconstruct historically established paradigms. Education must go beyond academic limits and strengthen the democratization of knowledge.
\end{abstract}

Keywords: Digital tools; Remote teaching; Reports; Asynchronous activities.

Topic: Ensino Superior, Pesquisa e Extensão

Reviewed anonymously in the process of blind peer.
Received: 11/11/2019

Approved: 10/03/2020
Wesley Pinto Hoffmann (D)

Universidade de Passo Fundo, Brasil

http://lattes.cnpq.br/5386628110517076

http://orcid.org/0000-0002-5814-1573

wesleywph@gmail.com

Sumaya Ferreira Guedes (iD)

Universidade do Estado de Mato Grosso, Brasil

http://lattes.cnpq.br/8709866585453750

http://orcid.org/0000-0002-1676-6030

su sumaya@yahoo.com.br

Claudineia Aparecida Queli Geraldi (iD)

Universidade do Estado de Mato Grosso, Brasil

http://lattes.cnpq.br/0165106391032005

http://orcid.org/0000-0001-5255-9752

claudigeraldi@onda.com.b

\author{
Sumaria Sousa e Silva (iD) \\ Universidade do Estado de Mato Grosso, Brasil \\ http://lattes.cnpq.br/9221384636856458 \\ http://orcid.org/0000-0001-7901-1316 \\ sumariasousa@gmail.com \\ Felicia de Araújo Lima (D) \\ Universidade do Estado de Mato Grosso, Brasil \\ http://lattes.cnpq.br/8673074137514866 \\ http://orcid.org/0000-0001-6301-8943 \\ fe.a.lima@hotmail.com \\ Raquel Aparecida Loss \\ Universidade do Estado de Mato Grosso, Brasil \\ http://lattes.cnpq.br/3925129970802016 \\ http://orcid.org/0000-0002-6022-7552 \\ raquelloss@unemat.br
}

Referencing this:

HOFFMANN, W. P.; GUEDES, S. F.; GERALDI, C. A. Q.; SILVA, S. S.; LIMA, F. A.; LOSS, R. A.. Relato de possibilidades de ensino com ferramentas digitais em tempos de pandemia. Justitia Liber, v.2, n.1, p.52-61, 2020. DOI: http://doi.org/10.6008/CBPC2674-6646.2020.001.0006 


\section{INTRODUÇÃO}

A constante atualização e globalização dos softwares em rede provocam mudanças acentuadas nos paradigmas sociais e políticos da sociedade, implicando em novos cenários para a comunicação digital. As experiências com ensino também têm suas metodologias modificadas, e consequentemente reflexos dessas modificações na construção de aprendizados entre estudantes (CHARTIER, 2007).

Conforme Moreira et al. (2020), mesmo com o fato de que as ferramentas de inserção digital em cursos e aulas eram pautas de discussão de metodologias ativas de ensino, foi difícil indagar sobre uma mudança rápida e emergencial, como a mudança provocada pela expansão da pandemia provocada pelo Coronavírus. Tal vírus provocou suspensões indeterminadas em aulas presenciais em todos os continentes, além de alterações pedagógicas, fazendo com que práticas estabelecidas tivessem de se reinventar rapidamente.

Os desafios de uma integração às ferramentas digitais em caráter de urgência são inúmeros. De acordo com Monteiro et al. (2015), é necessário transpor as concepções do ensino remoto para a educação em rede. Mais do que uma simples justaposição de práticas presenciais no ensino, é preciso criar modelos de aprendizagem colaborativos e construtivistas em plataformas selecionadas. Dados os desafios do ensino remoto, o problema de pesquisa do presente estudo delimita-se: Como agregar práticas sociais atrativas no ensino remoto emergencial?

As dificuldades financeiras e necessidades readaptação ao mercado de trabalho em um período de pandemia impulsionou a busca por cursos e capacitações que oferecessem conteúdo de qualidade, gratuito e sem a necessidade de deslocamento, dado as condições impostas pelo vírus causador da COVID-19. A produção de alimentos caseiros se mostra uma alternativa viável e bastante requerida, sendo que um curso promovido por uma universidade com a utilização de ferramentas digitais se mostrou uma oportunidade de inserção no mercado de trabalho e de renda extra para muitas pessoas que necessitam de autonomia e condições dignas para sustento.

O objetivo deste estudo é relatar as possibilidades de ensino em práticas desenvolvidas em um curso em ambiente virtual. Conforme Prodanov et al. (2013) este artigo apresenta abordagem qualitativa e procedimentos exploratórios e documentais, tendo em vista a análise de aportes teóricos que servem de embasamento para a pesquisa. Utilizamos as contribuições de Chartier (1998), Freire (1983), e outros estudiosos que se dedicaram a compreender as relações de estudo, sobretudo no contexto virtual de aprendizagem.

\section{METODOLOGIA}

A pesquisa foi desenvolvida de forma bibliográfica (através de artigos, dissertações, livros e meios digitais) e quantitativa, aliando a teoria aos dados obtidos a partir do preenchimento das planilhas de inscrição pelos participantes do curso. Conforme Prodanov et al. (2013) este artigo apresenta uma abordagem qualitativa e procedimentos exploratórios e documentais, tendo em vista a análise de aportes 
teóricos que servem de embasamento para a pesquisa. Utilizamos as contribuições de Chartier (1998), Freire (1983), e outros estudiosos que se dedicaram a compreender as relações de estudo, neste caso, em ambientes virtuais de aprendizagem.

\section{Inscrição e organização do curso}

O curso intitulado 'Boas Práticas na Fabricação de Bolo de Pote em Época de Pandemia' foi promovido pela Universidade de Mato Grosso (UNEMAT), por meio do ambiente virtual LanaLab ${ }^{1}$.

As inscrições foram realizadas no período de 15 a 20 de julho de 2020, por meio de preenchimento de um formulário virtual da plataforma Google Forms, devendo constar os seguintes dados: Nome, CPF, se possuía vínculo com a UNEMAT, Cidade e estado em que residia e motivo pelo qual se inscreveu no curso.

O período de duração do curso foi de 25 de julho a 15 de agosto. A organização do curso se deu por professores da área de alimentos da UNEMAT. O material ofertado abordou três módulos, conforme mostrado na Figura 1.

\begin{tabular}{|c|c|c|}
$\begin{array}{c}\text { Módulo 2 - Como } \\
\text { alimentar e os cuidados na } \\
\text { cozinha }\end{array}$ & $\begin{array}{c}\text { higienizar adequadamente } \\
\text { as superfícies antes do } \\
\text { trabalho? }\end{array}$ \\
$\begin{array}{c}\text { Módulo } 3 \text { - Dicas e receitas } \\
\text { de bolos de pote }\end{array}$
\end{tabular}

Figura 1: Módulos do curso remoto ofertado pela UNEMAT.

Além das apostilas criadas para estudo, os principais tópicos abordados em cada módulo foram disponibilizados em forma de vídeos. Ao final de cada módulo, o participante realizou uma avaliação contendo 10 questões acerca dos conteúdos abordados no módulo de estudo, cada avaliação pode ser refeita apenas uma vez, sendo necessário obter no minimo $70 \%$ de aprovação em cada módulo, ou seja, sete acertos em cada avaliação.

Ao finalizar as avaliações, os participantes responderam um questionário de satisfação, podendo elencar pontos positivos, negativos e sugestões de melhorias para futuras edições. Um certificado de participação de $20 \mathrm{~h}$ foi emitido pela UNEMAT para todos os participantes concluintes do curso em questão.

\section{Análise de dados}

Os dados gerados a partir do preenchimento da planilha do Google Forms no ato da inscrição, foram plotados em forma de gráficos utilizando o software Microsoft Excel $365^{\circ}$.

\section{DISCUSSÃO TEÓRICA}

Nesta seção, apresentaremos pressupostos teóricos basilares ao objetivo proposto em nossa pesquisa. A seção está subdividida em "Constituição de materiais digitais", que trata da produção de

\footnotetext{
${ }^{1}$ http://lanalab.com/site/index.html
} 
conhecimentos em ambiente digital e "Caminhos para a autonomia", onde discorremos sobre pressupostos de Freire (2005) fundamentais para a promoção à autonomia.

\section{Constituição de materiais digitais}

São poucas as instituições de ensino superior no Brasil que adotam um modelo híbrido entre atividades presenciais e atividades virtuais. A inserção do ensino digital precisa ser precedida de intenso planejamento, além de qualificação para os docentes e discentes protagonistas do conhecimento. Conforme Fernandes et al. (2020), o ensino digital deve levar em consideração as relações com o meio digital e a internet, com metodologias próprias para a modalidade específica da cibercultura.

A educação em rede requer o envolvimento de todos os participantes, seja na reunião para a definição de todos os objetivos e todo o percurso a ser traçado para a aprendizagem em comunidade, ou nas relações entre os estudantes nos processos de criação de outros conteúdos. O acesso assíncrono, ou seja, não simultâneo, promove o livre acesso de conteúdos e tecnologias em períodos pandêmicos (GOULÃO et al., 2014). Em função dos processos de globalização tecnológica, novos manejos digitais interferem nas instituições de ensino e todo o trabalho, tanto de docentes, como por discentes.

A flexibilidade ensino é uma demanda de estudantes que requerem liberdade para escolher os horários e espaços mais viáveis para o estudo, sobretudo em tempos de pandemia da COVID-19. Sendo assim, a Universidade do Estado de Mato Grosso (UNEMAT) propôs o curso intitulado "Boas Práticas na Fabricação de Bolo de Pote em Época de Pandemia", buscando promover práticas úteis aos cursistas com a facilidade no ensino assíncrono. Os desafios para a implementação de atividades assíncronas são diversos, sendo que a disponibilização de materiais de qualidade, atrativos e úteis se mostram características essenciais para essa modalidade de ensino.

O texto eletrônico converge várias linguagens, reunindo em um único suporte várias informações. Essa convergência funciona em lógica de rede. Em consonância com Chartier (1998), um produtor de um conteúdo online pode ser também um editor, já que dá forma ao que será difundido em ambiente virtual.

Em consonância com Schittine (2004), os blogs e ambientes virtuais de aprendizagem permitem cada vez mais a personalização facilitada de conteúdo. Todos os participantes podem produzir e participar de atividades mais propícias para o momento. Há uma tendência à produção individual de conteúdos e partilha no ambiente virtual de aprendizagem com todo o grupo de estudos.

De acordo com Chartier (2007), passamos de um antigo horizonte onde as linguagens estavam centralizadas e organizadas verticalmente pelos veículos de comunicação massiva, para um momento no qual a internet modifica o panorama de formação dos textos em ambiente digital, em possibilidades tecnológicas evidenciadas especialmente em blogs e páginas de softwares de criação livre. Esse processo resulta na personalização de conteúdos, como exemplificado na Figura 2.

Em conformidade com Dick et al. (2017), as publicações digitais estão envolvidas em diferentes áreas do conhecimento, sendo que há oportunidades em variados segmentos. As potencialidades das ferramentas em meio digital ampliam as possibilidades de trato de mídias e exploração de recursos do tempo, espaço em 
ambiente virtual e de aprendizagem, mídias e interações nas possiblidades de softwares online advindos da web 2.0. Conforme Chartier (1998) o cenário apresenta desafios às concepções de autoria em obras e materiais disponibilizados online, de modo que os materiais dispostos em cursos assíncronos não podem mais ser delimitados a um único detentor de direitos de elaboração e de distribuição em rede.

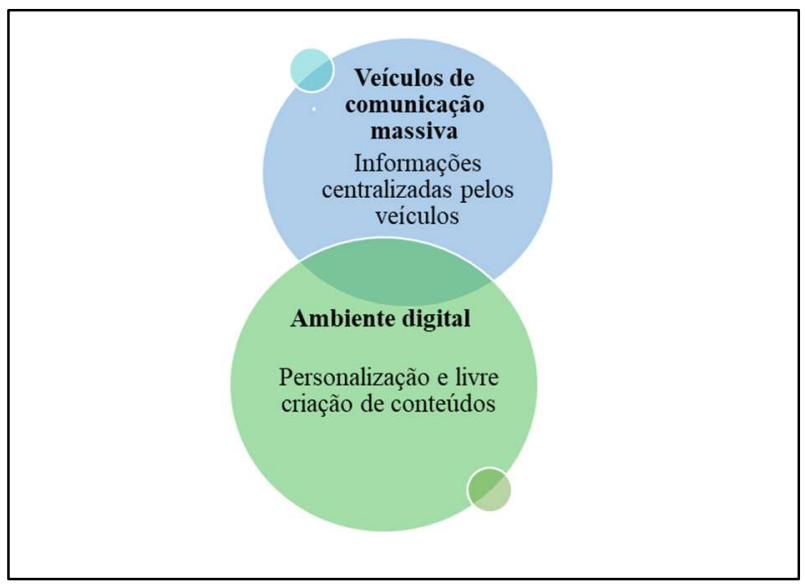

Figura 2: Processo de criação de conteúdo.

De acordo com Dick et al. (2017), os materiais produzidos em cursos digitais em tempos de pandemia são produzidos em layouts fluidos, cuja visualização e configuração dos arquivos se adaptam conforme o equipamento e as preferências do usuário em particular, além de serem interativos e agregarem diferentes mídias, como a imagem, texto escrito, som, vídeo e efeitos visuais.

A produção de materiais online pode ser dividida em cinco eixos e três subeixos adjacentes: Conceito, conteúdo (com presença dos subeixos de organização e fluxo de informações), Funcionalidades, Experiência (com presença do subeixo da Usabilidade), e eixo da Superfície. Assim sendo, o eixo referente ao Conceito envolve todas as definições prévias da publicação virtual, que alteram o panorama de realização de todos os outros eixos. As alternativas definidas auxiliam a clara definição, com vistas ao maior e melhor alcance de materiais produzidos em cursos online, como o curso "Boas Práticas na Fabricação de Bolo de Pote em Época de Pandemia" (DICK et al., 2016).

Relacionando os eixos ao uso de tecnologias, o eixo das Funcionalidades reúne recursos interativos de publicações, além de funcionalidades de suporte em nuvem. $O$ eixo a Experiência se ocupa da experiência de usuário e ergonomia, com seu respectivo subeixo 'Usabilidade'. Por fim, o eixo da superfície se ocupa da dimensão de apresentação e visualização de conteúdo. Vale ressaltar que os limites entre os eixos são conceitualmente difusos, com pontos de ligação, nos quais as decisões de um eixo influenciam em outras dimensões. As escolhas tomadas no eixo da Superfície podem destacar as relações de formação de layout e preferências de distribuição das informações (DICK et al., 2017). Ilustramos os conceitos apresentados a seguir, na Figura 3.

$\mathrm{Na}$ Figura 3, podemos observar que todos os processos de criação de conteúdo digital estão interdependentes e expostos através da superfície, que revela todas as características visuais expostas pelos materiais produzidos, como no caso dos cursos assíncronos. Mas como podemos compreender essas tecnologias em tempos de pandemia nos institutos de ensino? Na próxima subseção, intitulada 'Caminhos 
para a autonomia' versaremos sobre a importância da aprendizagem digital significativa relacionando essas reflexões aos dados obtidos sobre a realização do curso assíncrono promovido pela UNEMAT.

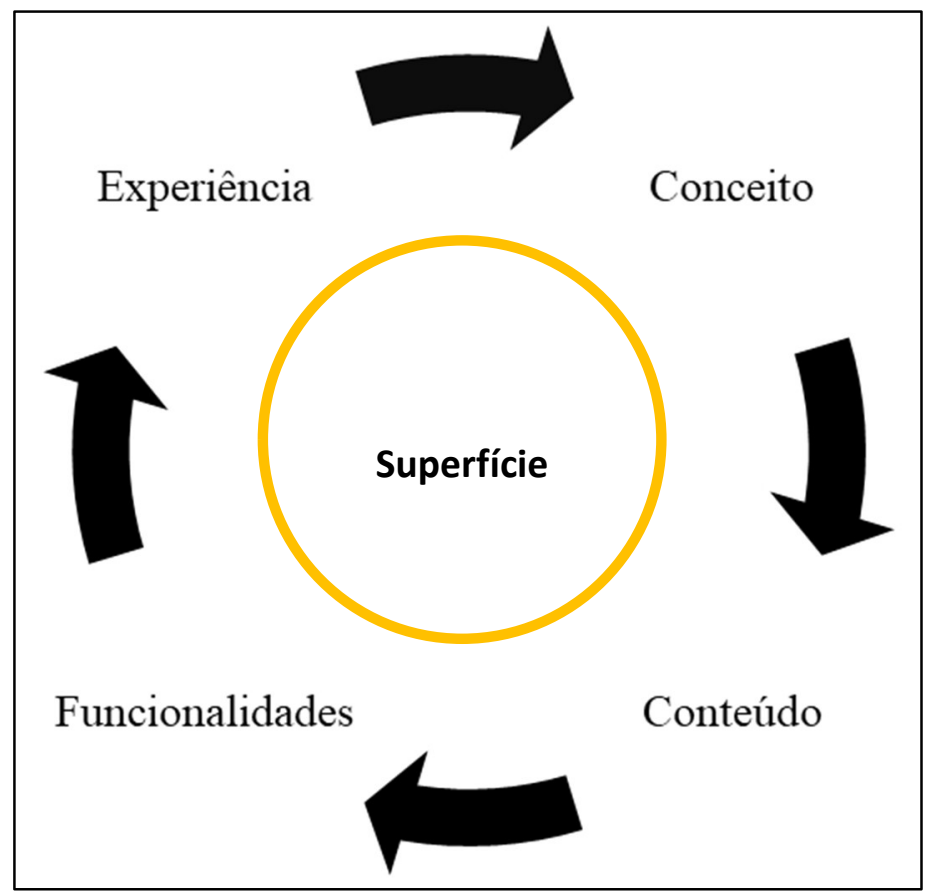

Figura 3: Eixos da produção de materiais online.

\section{Caminhos para a autonomia}

A mais recente Pesquisa Nacional por Amostra de Domicílios Contínua de 2018, divulgada pelo Instituto Brasileiro de Geografia e Estatística mostrou que 1 a 4 brasileiros não possui acesso à internet, e isso é um problema na inserção de práticas de ensino interativas e colaborativas. A educação tem o poder de alterar o panorama de enfrentamento à crise aclarada com o vírus.

Através da educação, é possível reconhecer os desafios impostos pela pandemia de Coronavírus, e planejar possibilidades de reinvenção e enfrentamento à crise humanitária e sanitária despertada pelo vírus. Conforme Mészaros (2005), a educação tem um papel de mudança social:

[...] O papel da educação é soberano, tanto para a elaboração de estratégias apropriadas e adequadas para mudar as condições objetivas de reprodução, como para a automudança consciente dos indivíduos chamados a concretizar a criação de uma ordem social metabólica radicalmente diferente. (MÉSZAROS, 2005)

A pandemia intensificou processos excludentes que há décadas vinham se manifestando, mas que no ano de 2020, foram evidenciados. A mais recente Pesquisa Nacional por Amostra de Domicílios Contínua de 2018, divulgada pelo Instituto Brasileiro de Geografia e Estatística mostrou que 1 a 4 brasileiros não possui acesso à internet, e isso é um problema na inserção de práticas de ensino interativas e colaborativas.

Apesar dos desafios e problemas relacionados ao acesso precário e desigual às tecnologias digitais, é notório que as ferramentas de interação e produção em ambientes virtuais de aprendizagem têm sido uma alternativa viável e produtiva na promoção e democratização da construção de conhecimentos. Em consonância com Romão (2012), a população precisa se reconhecer como protagonista da própria história através da consciência de transformação despertada pela educação. 
O Patrono da Educação Brasileira, Freire (2014), reflete em sua obra intitulada Pedagogia do Oprimido sobre a prática da liberdade que só localiza a expressão em uma pedagogia na qual os estudantes tenham condições de se descobrir e refletir como sujeitos de seus próprios destinos históricos. Podemos observar, a seguir, na Figura 4, a relação de estudantes vinculados e não vinculados a UNEMAT, que realizaram o curso de boas práticas, e, então, refletiremos sobre as hipóteses e aportes teóricos que a que recorremos.

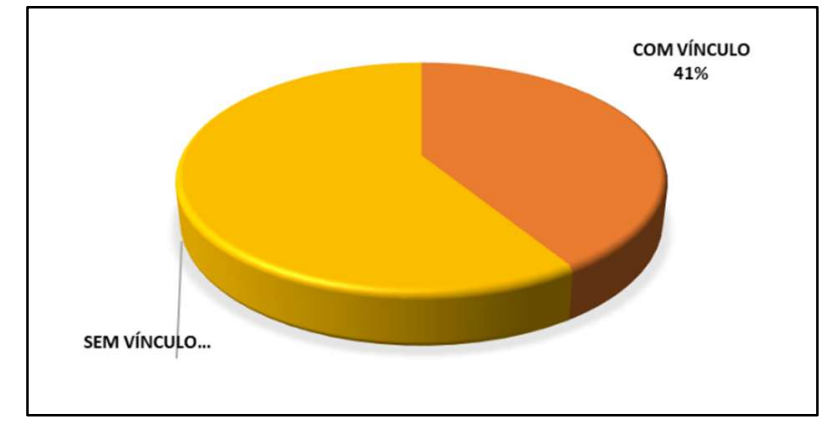

Figura 4: Vínculo dos participantes do curso com a UNEMAT.

Foi possível constatar que mais da metade, ou seja, $59 \%$ dos participantes do curso online promovido pela Universidade do Estado de Mato Grosso, não têm vínculo com a Universidade, sendo uma expressiva parcela constituída de pessoas da comunidade externa que querem agregar novos conhecimentos e não fazem parte do meio acadêmico da Universidade em questão. Mesmo com os diversos desafios impostos pela pandemia, é possível observar que a otimização de plataformas online para a disponibilização de cursos possibilita a ampliação de alcance em cursos e palestras promovidas por universidades, haja vista que esses eventos na modalidade online não requerem deslocamento físico.

O universo temático do povo deve servir como propulsor para os conteúdos da educação, sendo que essa prática inaugura o diálogo na educação como uma prática de liberdade. Apple et al. (1998) destacam que a disputa ideológica pela educação progressista não separa a formação técnica da preparação política, assim como a leitura de mundo ou a leitura de determinados discursos.

O fato de boa parte dos cursistas não terem vínculo com a Universidade evidencia que a construção de saberes no curso não se deu em caráter de obrigatoriedade, mas sim de uma relevância temática que atraiu estudantes interessados em complementar a formação para o mercado de trabalho e preparação de bolos de pote como uma fonte de renda em tempos de pandemia, por exemplo. Os pressupostos de Paulo Freire enfocam na necessidade de as práticas de ensino serem atrativas e aliadas ao contexto sócio-históricopolítico dos indivíduos. Apresentamos, na sequência, a Figura 5, com um gráfico composto pela distribuição de Estados da Federação dos cursistas.

A figura com o gráfico apresenta um demonstrativo percentual da participação de cursistas por Estados da Federação. Ao total, foram 10 Estados de diferentes regiões que foram compreendidas no curso. Tal oportunidade foi ampliada devido às possibilidades de conexão remota. Na modalidade presencial, dificilmente haveria um número expressivo de participantes de outras regiões, já que o deslocamento físico 
é um empecilho. As ferramentas digitais assíncronas adotadas foram fundamentais para a promoção do curso, em nível nacional, o que agregou às práticas desenvolvidas nas atividades online.

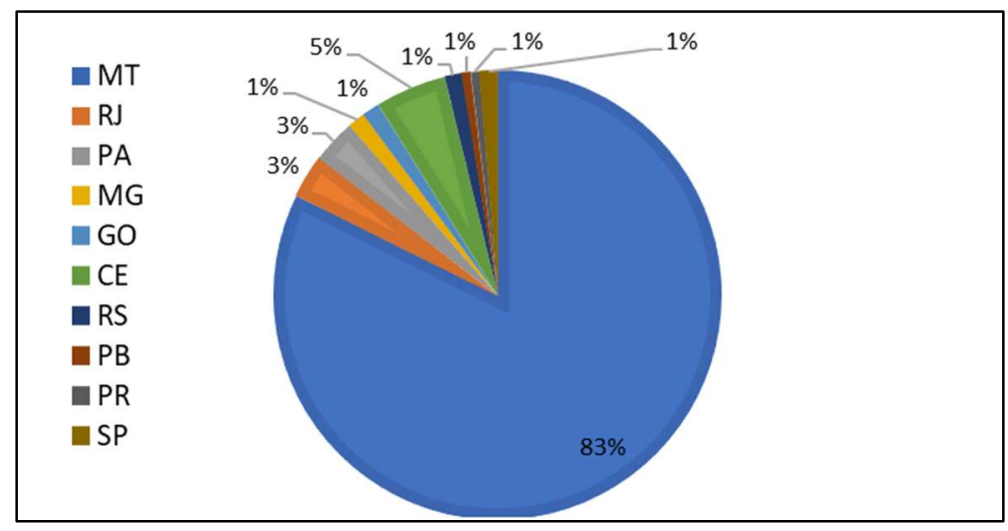

Figura 5: Participação por Estados da Federação.

Conforme Braga (2012), o papel da escola e instituições de ensino é defender a luta pela qualidade social da educação, incluindo todos na sociedade a partir de formação técnica, pedagógica, humana e política, engajando todos os participantes aos saberes coletivos. Os espaços precisam provocar ação, reflexão e devem incorporar as formas de ler e participar ativamente no mundo. A promoção de um curso em espaço virtual de aprendizagem tem muitos desses princípios, uma vez que possibilita o acesso gratuito e de qualidade a materiais que serão discutidos nas práticas e analisados, conforme o contexto especifico dos cursistas. Na Figura 6, por fim, apresentamos as motivações que levaram os cursistas a se inscreverem no curso.

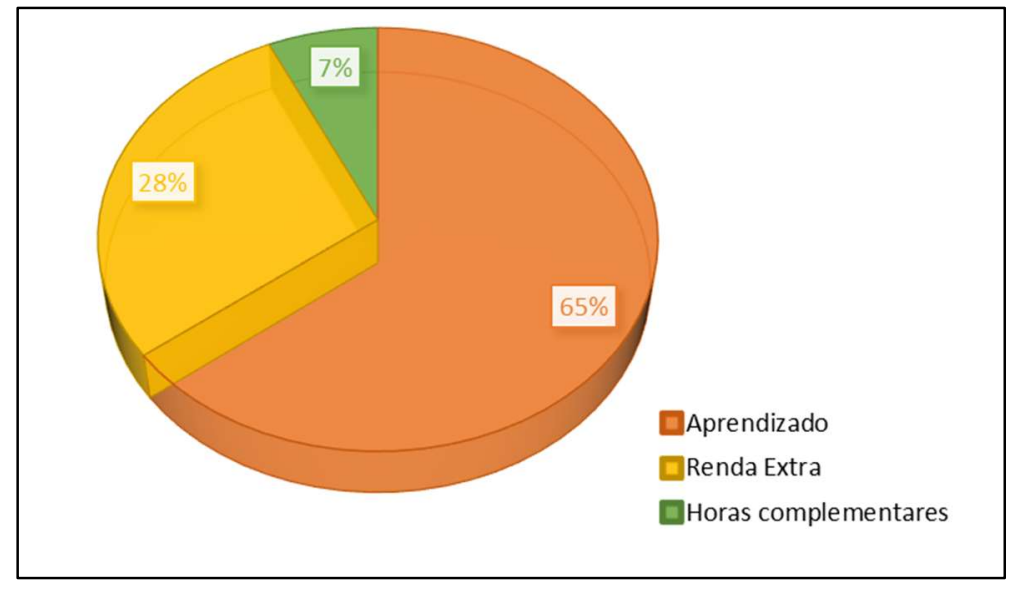

Figura 6: Motivação para inscrição.

É perceptível que o curso não foi realizado como caráter de obrigatoriedade, mas sim, a partir dos interesses e necessidades dos estudantes, o que corrobora com os pressupostos de Paulo Freire apresentados neste estudo. A autonomia para a tomada de decisões é basilar nas pesquisas de Paulo Freire. $65 \%$ dos participantes inscreveram-se com o intuito de construir novos aprendizados úteis. Cabe destacar a significativa participação de $28 \%$ dos cursistas que se inscreveram no intuito de garantir renda extraem tempos de pandemia, o que é valoroso na busca da autonomia e superação de desafios impostos pelos impactos do Coronavírus na realidade brasileira. 
No contexto das práticas pedagógicas que se caracterizam como humanizadoras, fundadas na aprendizagem, que têm como ponto de partida e de chegada à realidade social, 0 empoderamento pode se constituir como processo dinâmico, inconcluso de assunção de espaços e tempos conquistados com ética, autenticidade e reivindicação de direitos. (BRAGA, 2012)

Transcrevemos, na sequência, dois relatos fornecidos por participantes do curso na modalidade assíncrona: "Um curso maravilhoso, só tenho de agradecer a todos por disponibilizar esse conteúdo que sem dúvida vai me ajudar bastante no âmbito profissional” (L.M.). "Com base na minha experiência no curso, foi consideravelmente boa minha participação, informações diretas, conteúdo de fácil entendimento e útil para o meu trabalho" (G.C.).

A prática pedagógica a partir dos estudos de Freire (2005) se orienta pela premissa do direito das camadas populares à educação, uma pedagogia da autonomia. Em conformidade com Braga (2012), o empoderamento é um exercício permanente da autonomia, e a autonomia também é promovida quando os cursistas são instigados a construírem conhecimentos úteis para a independência financeira, e não são mais dependentes de empresários e detentores de conhecimentos para produção de alimentícios, como o bolo de pote. Nesse movimento, os cursistas ganham poder libertário para se expressar e defender seus direitos, por meio de práticas educacionais em ambiente virtual de aprendizagem.

\section{CONCLUSÕES}

A educação precisa funcionar como subsídio para a transformação social e construção da autonomia, como pressuposto para suporte nas desconstruções de paradigmas de classes sociais. A educação deve ultrapassar os limites acadêmicos e romper contextos de opressão e de ausência de relações democráticas.

A busca por relações significativas de aprendizado com ferramentas digitais em tempos de pandemia não é uma tarefa fácil, sendo que nenhuma outra metodologia substitui o contato e relações presenciais, mas as ferramentas à disposição dos estudantes em modalidade assíncrona se mostraram viabilizadoras de construções de conhecimentos.

O problema de pesquisa apresentado na pesquisa foi delimitado da seguinte maneira: Como agregar práticas sociais atrativas no ensino remoto emergencial? $\mathrm{O}$ que se comprovou com as reflexões sobre o ensino que preza o contexto dos estudantes e a promoção à autonomia, como a realização do curso virtual 'Boas Práticas na Fabricação de Bolo de Pote em Época de Pandemia'. O objetivo deste estudo foi relatar as possibilidades de ensino em práticas desenvolvidas em um curso em ambiente virtual, como discorremos nas discussões apresentadas sobre as ferramentas digitais disponíveis para o ensino em rede.

Há inúmeras dificuldades e desigualdades no acesso às ferramentas virtuais no Brasil. O ensino remoto e todas as implicações das tecnologias em tempos de pandemia podem ser mais discutidas em outras pesquisas, tendo em vista o breve espaço estrutural de um artigo científico, considerando a abrangência dos temas abordados neste artigo. É fundamental repensar o uso das tecnologias como metodologias de ensino ativas, que valorizam o conhecimento e contexto social de todos os participantes da construção de saberes.

Finalmente, como perspectiva para futuras pesquisas, esperamos que outros autores também se empenhem em pesquisar sobre as possibilidades e atividades realizadas com ferramentas virtuais em 
períodos de pandemia, para que a discussão seja cada vez mais valorativa. $\mathrm{O}$ ensino virtual e as atividades remotas necessitam de um olhar mais amplo e dedicado a aproveitar todas suas potencialidades.

\section{REFERÊNCIAS}

APPLE, M. W.; NÓVOA, A.. Paulo Freire: política e pedagogia. Porto: Porto, 1998.

BRAGA, M. M. S. C.. Prática pedagógica docente-discente e humanização: contribuição de Paulo Freire para a escola pública. Recife: UFPE, 2012.

CHARTIER, R.. A aventura do livro do leitor ao navegador: uma conversa com Jean Lebrun. São Paulo: Unesp, 1998.

CHARTIER, R.. Inscrever e apagar. São Paulo: Unesp, 2007.

DICK, M. E.; GONÇALVES, B. S.. Publicações digitais: um panorama sobre design e tecnologia. 2017.

DICK, M. E.; GONÇALVES, B. S.. Consulta a especialistas como procedimento de avaliação de orientações para o design de publicações digitais sistemáticas. Blucher Design Proceedings, v.2, n.9, p.1535-1546, 2016.

FERNANDES, S. M.; HENN, L. G.; KIST, L. B.. O ensino a distância no Brasil: alguns apontamentos. Research, Society and Development, v.9, n.2, p.19, 2020.
FREIRE, P.. Pedagogia da autonomia: saberes necessários à prática educativa. São Paulo: Paz e Terra, 2005.

FREIRE, P.. Pedagogia da esperança: um reencontro com a pedagogia do oprimido. São Paulo: Paz e Terra, 2014.

GOULÃO, M. F.; BARROS, D.. Recursos educacionais abertos na prática pedagógica: estratégias, estilos e autorregulação da aprendizagem. Educação a Distância e Elearning na Web Social, p.129-152, 2014

MÉSZAROS, I.. Para além do capital: rumo a uma teoria da transição. Boitempo, 2015.

MONTEIRO, A.; MOREIRA, J. A.; LENCASTRE, J. A.. Blended (e) learning na sociedade digital. Whitebooks, 2015.

PRODANOV, C. C.; FREITAS, E. C.. Metodologia do trabalho científico: métodos e técnicas da pesquisa e do trabalho acadêmico. 2 ed. Feevale, 2013.

SCHITTINE, D.. Blog: comunicação e escrita íntima na internet. Record, 2004.

A CBPC - Companhia Brasileira de Produção Científica (CNPJ: 11.221.422/0001-03) detém os direitos materiais desta publicação. Os direitos referem-se à publicação do trabalho em qualquer parte do mundo, incluindo os direitos às renovações, expansões e disseminações da contribuição, bem como outros direitos subsidiários. Todos os trabalhos publicados eletronicamente poderão posteriormente ser publicados em coletâneas impressas sob coordenação da Cognitionis Publishing, da Companhia Brasileira de Produção Científica e seus parceiros autorizados. Os (as) autores (as) preservam os direitos autorais, mas não têm permissão para a publicação da contribuição em outro meio, impresso ou digital, em português ou em tradução. 